National Marrow Donor Program - be set up to ensure a standardized and interconnected national system to cost-effectively store and distribute these cells. The Bush administration is studying the IOM report but has not yet determined its next step.

The proposed center would strengthen the network of cord blood banks and allow physicians to meet the needs of more patients who require transplantation therapies with a high-quality stem cell product, Rocha said. To build an adequate supply of cord blood for transplantations, the IOM concluded that the nation would need about 100,000 donations, in addition to the useable 50,000 cord blood donations already in stock at various public cord blood banks around the country.

Increasing the amount of inventory would assure that more people find a suitable match. "The matched cells are useful because they are frozen, so one does not need to depend on a live donor's availability," Luban told the JCI. But, she adds, "One cannot go back to the donor for additional transplantable cells or for other donor-derived cells.”

Another factor that restricts the clinical utility of cord blood stem cells is that use of these cells to treat other patients, called allogenic transplantation, could be associated with recipient immune rejection against donor cells. According to Luban, the small volume and low percentage of cells expressing CD34, an antigen selectively expressed on human hematopoietic progenitor cells, are also limiting factors.

The limitations due to the fact that cord blood stem cells are rare can be resolved through new expansion techniques, said Jonathan Leor, head of the Neufeld Cardiac Research Institute at Sheba Medical Center in Tel Aviv. Based on his experience, Leor believes that there is a high probability that the cells obtained from cord blood could be expanded in vitro and used for myocardial repair and angiogenesis. Clinical trials are also underway to assess the effects of using 2 cord blood units for a single patient, Rocha said.

Most important, many recent clinical retrospective studies in children and in adults show that the results of unrelated cord blood cell transplants are similar to those of unrelated bone marrow transplants. "Transplantation in children tends to have a good outcome with a minimum dose of cells," said Derwood Pamphilon, a consulting hematologist for the United Kingdom's National Blood Service. Even in adults, he continued, a reasonable dose of cord blood cells, even with a minor degree of mismatch, gives an outcome much better than had been hoped for.

\section{Stacie Bloom}

\title{
The life sciences, according to Didier Trono
}

$D$ idier Trono has been dean of the School of Life Sciences, a new entity at The Swiss Federal Institute of Technology Lausanne (EPFL), since October 1, 2004. The JCI talked to Trono, a prominent HIV researcher and former clinician, about his first 6 months on the job and about the ups and downs of starting a life sciences school at a renowned technology institute.

JCI: How were you selected for this position?

Trono: I was selected through an international search process. JCI: What are your main goals as dean?

Trono: The School of Life Sciences is the new kid on the block at EPFL, born from the strong belief that biomedical research will reach new frontiers by integrating quantitative approaches and technologies yielded by the hard sciences. There is an incredible thirst for biological questions amongst our colleagues here from chemistry, physics, mathematics, computer science, engineering, and so on. Also, the EPFL bachelor and master programs, its very international faculty, and its lakeside campus attract some of the very best students not only from Switzerland and other European countries but also from the rest of the world.

[This is] a unique opportunity to create a top-level biomedical research institution, where the traditional life sciences fortes of the Geneva-Lausanne region, in genetics, molecular and cellular biology, are taken to new dimensions within the setting of a leading institute of technology. My responsibility as dean is to help this vision come true.

JCI: What does your research focus on?

Trono: The main focus of my laboratory has been for many years the molecular biology of HIV infection with, lately, a special interest in innate cellular factors that confer resistance against retroelements, be it HIV itself, hepatitis B virus, or endogenous retroelements. A few years back, our HIV work led us to develop lentiviral vectors. We keep exploring their potential for human gene therapy and as tools for the study of mammalian genetics.
JCI: Do you plan to continue this work, or are your duties mostly administrative now?

Trono: Basic research has been a passion from the day I entered David Baltimore's laboratory after completing my clinical training in infectious diseases, and I made it very clear before accepting the EPFL job that I would keep doing research. If anything, running a lab places me in a perfect spot to judge whether what we are putting

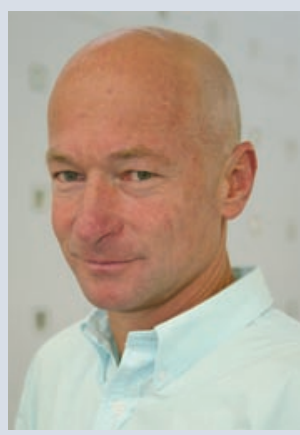

Didier Trono, dean of the new School of Life Sciences at EPFL. in place is working or not.

JCI: Will you describe your typical day?

Trono: Waking up a bit after 5, clearing up nightly e-mails, brushing through a newspaper for some update on the world, starting with the all-important sports section ... And that is about it for the routine. The rest is faculty recruitments, core facilities organization, discussions with architects on the building that will add 10,000 square meters of research space to our school within a couple of years. And many discussions with my colleagues on how best to foster our fast-growing programs in cancer research, developmental biology, neurosciences, infectious diseases, structural biology. And for dessert, breezing through the lab and debating with students and postdocs on the implications of their latest result and on the smartest way to get yet one step closer to [answering] the questions that keep us awake at night.

JCI: When you leave, what do you hope to have accomplished?

Trono: [To have] saved the world. But don't repeat it, in case I come up short ...

Stacie Bloom 